\title{
Characterization of Active Spawning Season and Depth for Eastern Pacific Halibut (Hippoglossus stenolepis), and Evidence of Probable Skipped Spawning
}

\author{
Timothy Loher \\ International Pacific Halibut Commission, P. O. Box 95009, Seattle, WA, USA 98145 \\ Email: Tim@iphc.washington.edu \\ and \\ Andrew C. Seitz \\ University of Alaska, Institute of Marine Science, P. O. Box 757500, \\ Fairbanks, AK, USA 99775
}

\begin{abstract}
Loher, T., and A. Seitz. 2008. Characterization of active spawning season and depth for eastern Pacific halibut (Hippoglossus stenolepis), and evidence of probable skipped spawning. J. Northw. Atl. Fish. Sci., 41: 23-36. doi: 10.2960/J.v41.m617
\end{abstract}

\begin{abstract}
The eastern Pacific halibut (Hippoglossus stenolepis) fishery is prosecuted over a nine-month season with a provision to cease harvests if stock declines to historically-observed minimum spawning biomass. The industry has requested to extend fishing into winter, but little information exists regarding potential impacts on spawning aggregations or effective spawning biomass. A strictly annual spawning cycle is presumed, but some adults fail to undertake the offshore migration associated with continental slope spawning. We examined depth records of halibut tagged with Pop-up Archival Transmitting (PAT) tags for evidence of offshore seasonal migration $(n=72)$. For tags that were physically recovered $(n=16)$ we identified the occurrence of abrupt $(\sim 100 \mathrm{~m})$ mid-winter ascents, believed to be egg release. The active spawning season, defined by occurrence of these rises, lasted from 27 December-8 March, at bottom depths of 278-594 m. Eighteen percent of tagged halibut remained onshore. Thirty-one percent of fish with detailed archival records did not exhibit spawning rises, including all fish that remained onshore. Correcting for the possibility that some were likely immature, the data suggest that $\sim 10 \%$ of the mature fish do not participate in the spawning migration and $10-15 \%$ that migrate to deep water may not actively spawn. The data suggest that opening the commercial fishery in early spring would likely subject actively spawning fish to fishing mortality, and could truncate the effective spawning period. Natural rates of skip-spawning and fisheries-induced reduction of the spawning period relative to suitable larval rearing conditions could introduce temporal and regional variance into levels of effective spawning biomass and warrant further investigation.
\end{abstract}

Key words: electronic archival tagging, migration, Pacific halibut, skipped spawning, spawning

\section{Introduction}

Pacific halibut (Hippoglossus stenolepis) (hereafter "halibut") represent one of the northeastern Pacific Ocean's most valuable fisheries resources, producing an average annual yield of $\sim 70$ million pounds $(32000 \mathrm{mt})$ of landed product, presently valued at approximately US $\$ 300$ million. Recent abundance levels have been among the highest ever recorded, with exploitable biomass peaking at roughly 400 million pounds (182 $000 \mathrm{mt})$ in 1998 and presently estimated at approximately 330 million pounds (150 $000 \mathrm{mt}$ ). Prior to the adoption of individual quota (IQ) management systems in Alaskan and Canadian waters, the International Pacific Halibut Commission (IPHC) achieved control of effort and total harvests primarily through adjustments to season length. In the late 1970s and early 1980s, economic incentives and increases in fleet power combined to result in continually shrinking seasons. By 1990 the Canadian commercial halibut season had been reduced to just ten days, and to just two or three days in the remainder of the Gulf 
of Alaska (GoA) and much of the southeast Bering Sea. In 1991 the IPHC adopted an Individual Vessel Quota (IVQ) system for Canada that allowed the season to be increased to 213 days, and in 1995 a similar Individual Fishing Quota (IFQ) program was implemented in Alaska that resulted in a 245 day fishery. The Alaskan and Canadian fisheries have remained at between 245 and 262 days over the last decade, but recent economic concerns have prompted industry to request that the IPHC examine the possible merit of a longer season, or potentially one that lasts the entire year.

Halibut in the eastern Pacific are believed to spawn from November through March, with peak spawning activity from late December to late January (St. Pierre, MS 1984). Since the inception of IQ management, the fishery has traditionally been closed from 15 November through early March, but IPHC staff has stated a belief that an extended season could be prosecuted without biological harm to the composite stock (Leaman et al., MS 2002). Modest increases in season length have recently been achieved by opening the commercial fishery earlier in the spring. From 1995-2002 the commercial fishery never opened prior to 15 March, whereas openings from 2003-2006 have occurred between 27 February and 5 March. However, extending harvests into the winter spawning season presents challenges and concerns. From a biological standpoint, research has shown that hook-and-line fisheries prosecuted during active spawning seasons can alter population sex ratios (Coleman et al., 1996; Hibberd and Pecl, 2007), presumably due to seasonally mediated sex-specific selectivity. Furthermore, spawning demographics may change throughout the season. Application of fishing mortality during only a portion of that season may introduce a selective force that can eliminate or reduce the abundance of behavioral genotypes that spawn during the open fishing period, altering population diversity, fitness, and resilience (Hansen and Jonsson, 1991; Hede-Jorgensen et al., 2005; Quinn et al., 2006; Moltschaniwskyj and Pecl, 2007).

Unfortunately, our understanding of halibut spawning dynamics is coarse-scale, and is not based on an understanding of in situ spawning behavior. The most comprehensive source is St. Pierre (MS 1984), who compiled data on spawning season and locations throughout the eastern Pacific, collected from a variety of sources from 1915-1982. His review provides a solid conceptual model of spawning season and geographic locations, but it is far from a quantitative analysis. The work is primarily a compilation of fleet observations and informal logbook entries regarding encounters with spawning fish. However, it fails to include formally-analyzed data from systematic surveys capable of quantitatively assessing spawn-timing in any region, nor does it contain a standardized definition of "spawning fish." In reality, we do not know precisely when halibut spawn, nor do we know what proportion of the stock participates in spawning in any given year.

Larval abundance surveys can provide an accurate method for characterizing the active spawning season because such surveys directly monitor the appearance of reproductive products within the water column. Abundance of halibut eggs has been sampled in situ. From 1935-1946, Van Cleve and Seymour (MS 1953) conducted extensive winter-long (December-March) plankton surveys in British Columbia and demonstrated that release of eggs peaks in January and occurs at modest levels throughout December and February. However, their work was limited to a single site at the southernmost edge of the known spawning range, and was conducted more than 50 years ago. Thus, it is difficult to know how applicable their results are to today's concerns regarding appropriate fishery-opening dates coastwide. Variability of weeks to months in the timing of peak spawn has been demonstrated for commercial roundfish (Slotte et al., 2000; Wieland et al., 2000) and flatfish (Harding et al., 1978; Lange and Greve, 1997) in the north Atlantic. Factors affecting spawn timing may include temperature (Lange and Greve, 1997; Wieland et al., 2000), fish size (Slotte et al., 2000), and age-composition of the spawning stock (Wieland et al., 2000). Variability may be environmentally driven or related to exploitation history, varying geographically and along depth gradients, and either relatively stochastic or temporally trended. For halibut, archival tagging data allow us to better quantify seasonal onshore-offshore movements and define the period when putative spawners are distributed on deepwater grounds. But we still do not know how long it takes individuals arriving on the grounds to form spawning aggregations and undertake potential pre-spawn courtship behavior, and therefore when active release and fertilization of eggs begins, nor do we have any understanding of regional or temporal variability in spawn-timing.

In addition to providing guidance for crafting appropriate season-opening dates, a better knowledge of spawning dynamics might also be useful for refining harvest policy. Halibut is presently managed via catch limits and exploitation rates that are scaled to regional biomass (Clark and Hare, 2006). The management plan calls for cessation of harvest if the stock declines to the historically-observed minimum spawning biomass (Clark and Hare, MS 2006), which is estimated by applying age-at-maturity data from annual surveys to abundance estimated via the numerical stock assessment. It 
is believed that halibut spawn annually upon reaching maturity (Leaman et al., MS 2002), but two lines of evidence provide reason to question this assumption.

Age-at-maturity is monitored through the IPHC's setline survey program. A total of 1233 survey stations are fished annually, fish ages are determined from otoliths, and maturity stages are assigned on the basis of external macroscopic gonad examination. Maturity ogives (Fig. 1) indicate that size-at-50\%-maturiy for the female population is presently around $90 \mathrm{~cm}$ fork-length (fl), with $100 \%$-maturity at $\sim 140 \mathrm{~cm}$ fl. However, much larger females are regularly encountered that are deemed to be immature on the basis of gonad examination. During the 2007 survey, the largest "immature" female measured $184 \mathrm{~cm}$, and an individual measuring $199 \mathrm{~cm}$ was assigned immature status in 2004. These observations have led to speculation that external gonad examination might be inadequate for assigning maturity for fish that are in a resting state between spawning periods, especially if some of those individuals would have failed to spawn (i.e., skipped spawning) the subsequent winter.

The hypothesis of skipped spawning in halibut is further supported by archival tagging data. The majority of halibut spend the summer feeding on the coastal shelf, migrate offshore in the autumn, and spawn along the continental slope during North American winter (December-March). In 2002 the IPHC began an electronic tagging program designed to investigate seasonal movements of halibut. Depth profiles from the majority of recovered tags confirm an autumn offshore migration period that extends from September through December, a winter deep-water residence phase, and return to shallow water typically in March-April (Loher and Seitz, MS 2006; Loher, 2008). However, some halibut failed to conduct such a migration, instead spending the entire year in shallow water on the continental shelf. This suggests that either some fish spawn on the shelf at grounds not yet identified, or a proportion of the population forgoes spawning each year and thus does not undertake the associated migration to the slope.

Rideout et al. (2005) warn that failing to account for foregone spawning can lead to difficulty in interpreting the relationship between total mature biomass and population reproductive potential, which can be particularly important where spawning biomass limits are used to guide harvest policy. In an analysis of reproductive potential of Canadian Atlantic cod (Gadus morhua) over a six-year period, Rideout and Rose (2006) estimated that more than half of all females could experience mass oocyte atresia in a single spawning season, and that reproductive suppression annually reduced population reproductive potential by $8-41 \%$. Burton (1999) presented data indicating considerable rates of foregone spawning for a number of northern flatfish species including winter flounder (Pleuronectes americanus), Greenland halibut (Reinhardtius hippoglossoides) and Atlantic halibut (Hippoglossus hippoglossus), and concluded that stockrecruitment relationships might be improved by accounting for reproductive non-participation.

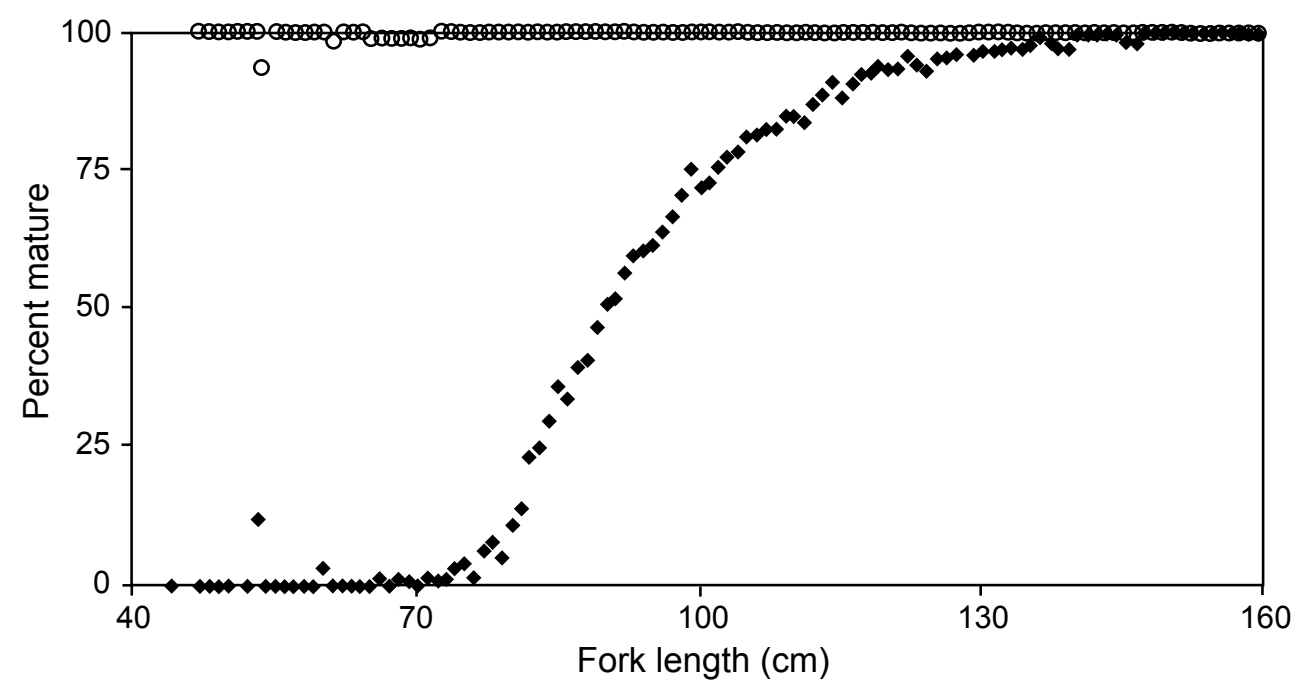

Fig. 1. Size-specific maturity of male (open circles; $n=22898$ fish) and female (closed diamonds; $n=31$ 666) Pacific halibut in the Gulf of Alaska, derived from 2006 International Pacific Halibut Commission setline survey data. The data describe maturation for females, whereas nearly all males vulnerable to the survey gear are already mature. 
The present study uses data from recent electronic archival tagging experiments to characterize active spawning depth and season, and estimate the proportion of the GoA halibut stock that fails to undertake the autumn spawning migration or actively participate in spawning. Of particular interest was to reassess the hypothesis that peak spawning occurs in January (St. Pierre, MS 1984), and that extending the commercial spawning season into February will have little impact on spawning fish. Additionally, we sought to evaluate the competing views that halibut are annual spawners (St. Pierre, MS 1984; Leaman et al., MS 2002) versus potentially biennial (Novikov, 1964).

\section{Materials and Methods}

\section{Tagging}

Three separate experiments were conducted between 2000 and 2006 utilizing Pop-up Archival Transmitting (PAT) tags that were programmed to remain on their host fish throughout the winter months, releasing no earlier than 15 February, thus providing an opportunity to monitor seasonal migration and mid-winter fish behavior. A total of 102 PAT tags were deployed throughout the Gulf of Alaska (Fig. 2). Five tags were deployed on 20 November 2000, programmed to release from their host fish on 15 June 2001 (Seitz et al.,
2003). Forty-eight tags were deployed between 8 June and 21 August 2005, programmed to release from their host fish after exactly 365 days at-liberty. Forty-nine tags were deployed between 2 June and 31 July 2006, 25 of which were programmed to release from their host fish on 15 February 2007 and 24 of which were programmed to release on 1 March 2007.

Fish ranged from 104-159 cm fl (Fig. 3); only halibut $>100 \mathrm{~cm}$ fl were tagged because halibut of this size have a high probability of being sexually mature (Clark et al., 1999; Fig. 1). Given sex-specific differences in size-at-age, these fish also have a $>90 \%$ probability of being female (Fig. 4). Tags were affixed to the halibut externally, about $2.5 \mathrm{~cm}$ medial to their dorsal fin on the eyed-side of the fish where the body began to taper towards the tail. Tags were tethered to titanium darts using $15 \mathrm{~cm}$ of $130 \mathrm{~kg}$ test monofilament fishing line wrapped in adhesive-lined shrink wrap. The darts were inserted through the dorsal musculature and pterygiophores, anchoring them in the bony fin-ray supports of the halibut. Each tag contained sensors that were programmed to record temperature and depth at one minute intervals and ambient light levels every two minutes.

For fish that were not captured by commercial or sport fisheries prior to the pre-programmed tag detachment date, the tags released from the host fish, floated to

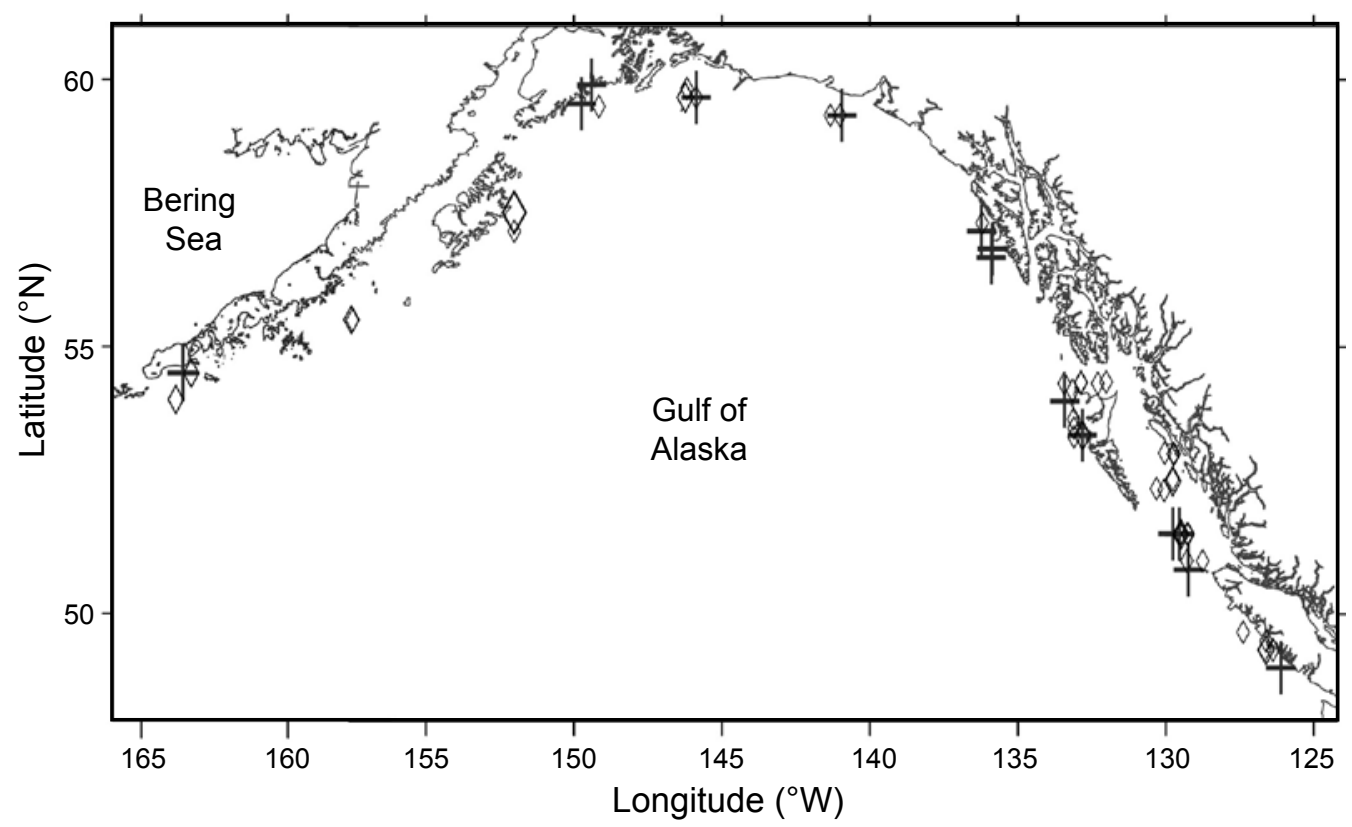

Fig. 2. Release locations for Pop-up Archival Transmitting tags $(n=72)$ deployed on Pacific halibut from 2000-2006. Crosses indicate deployment locations for tags that were physically recovered, and open diamonds indicate tags that reported data via satellite transmission. 


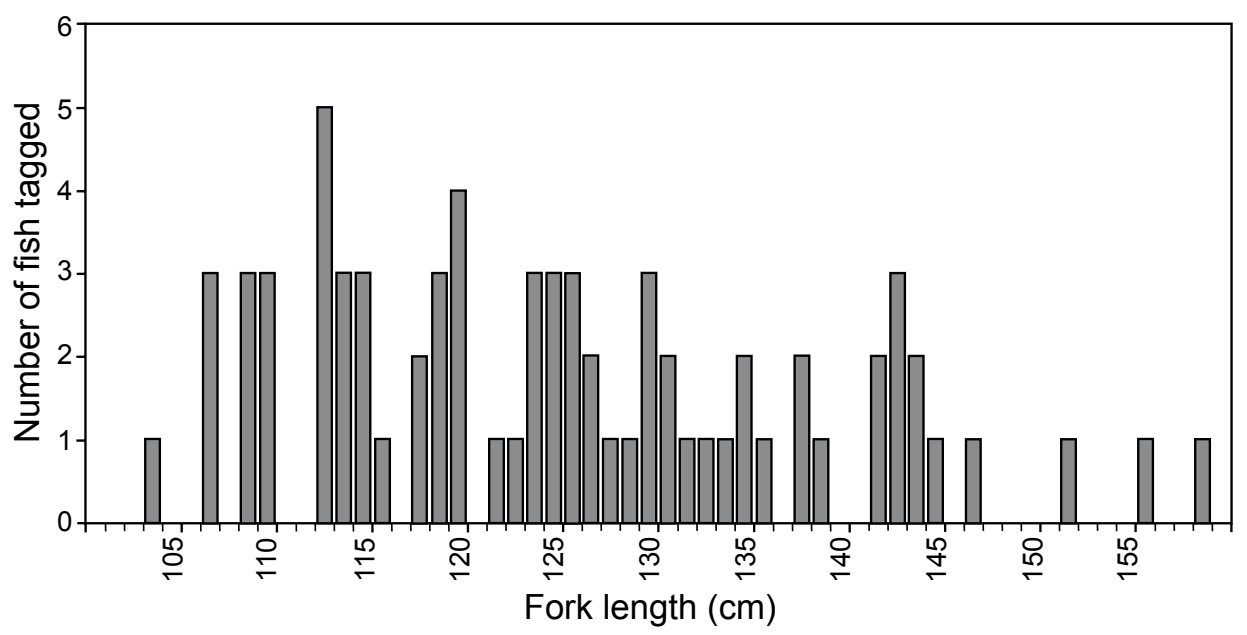

Fig. 3. Size-frequency distribution of the Pacific halibut $(n=72)$, tagged with Pop-up Archival Transmitting tags, that generated archival data reported in this study.

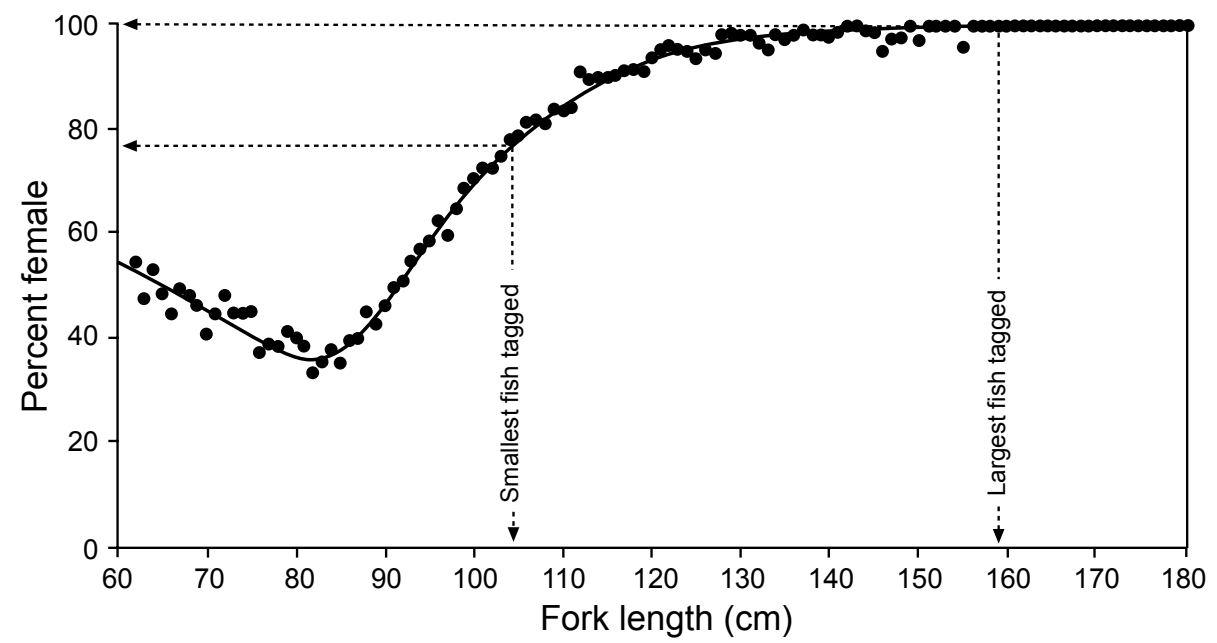

Fig. 4. Size-specific sex ratio of Pacific halibut in the eastern Pacific Ocean, derived from 2006 International Pacific Halibut Commission setline survey data $(n=53043$ fish). The range of fish sizes represented in this study are indicated by dashed arrows; there is a high probabilty that most fish tagged in this study were female.

the surface, and transmitted summarized historical data records to the US National Oceanic and Atmospheric Administration's (NOAA) polar-orbiting satellites, administered by the Advanced Research and Global Observation System (ARGOS). Data transmissions included percentage of time spent within specific depth ranges, and minimum and maximum depths visited during 12 hour summary periods, allowing reconstruction of onshore-offshore migration. Tags that were physically recovered, either while still on the host fish or awash following programmed release, were downloaded to provide minute-by-minute observations throughout the fish's time-at-liberty.

\section{Spawning rises}

Detailed archival records from physically recovered tags were examined for evidence of putative spawning behavior showing a series of abrupt ascents of 100-200 $\mathrm{m}$ in magnitude and each of $\sim 10$ minutes in duration (referred to hereafter as "spawning rises"), conducted during midwinter (sensu Seitz et al., 2005). This behavior is believed to represent active spawning because it closely parallels spawning behavior observed in situ in other flatfish species (Moyer et al., 1985; Konstantinou and Shen, 1995; Manabe et al., 2000; Manabe and Shinomiya, 2001; Carvahlo et al., 2003), and is consistent with the fact that halibut are serial (batch) spawners (St. Pierre, MS 1984). 
For each fish displaying spawning rises, their behavior was characterized using the following metrics: initiation date and time, initiation depth, apex depth, apex date and time, termination depth, termination date and time (Fig. 5). From these, ascent and descent durations ( $\mathrm{min}$ ) and rates $\left(\mathrm{m} \mathrm{min}^{-1}\right)$ were calculated, as well as mean intervals between each apex (min). Active spawning season and depth were characterized via frequency distributions of rise initiation date and rise initiation depth, respectively.

\section{Offshore migration}

Depth records from all tags were examined for evidence of offshore wintertime movement follow- ing reconstruction of daily maximum depth profiles. Fish were designated as having conducted the winter offshore spawning migration if they inhabited waters equal to or greater than the minimum observed spawning depth between 1 November and 1 April (i.e., a conservative estimate of the spawning season) for a period of at least three consecutive days. Fish were designated as non-migratory if they failed to move to the specified depth during the spawning season. Note that in this context, the designation of "migratory" refers only to onshore-offshore migration consistent with movement to deep-water spawning grounds, and does not preclude the possibility of having conducted potentially extensive longshore movements.

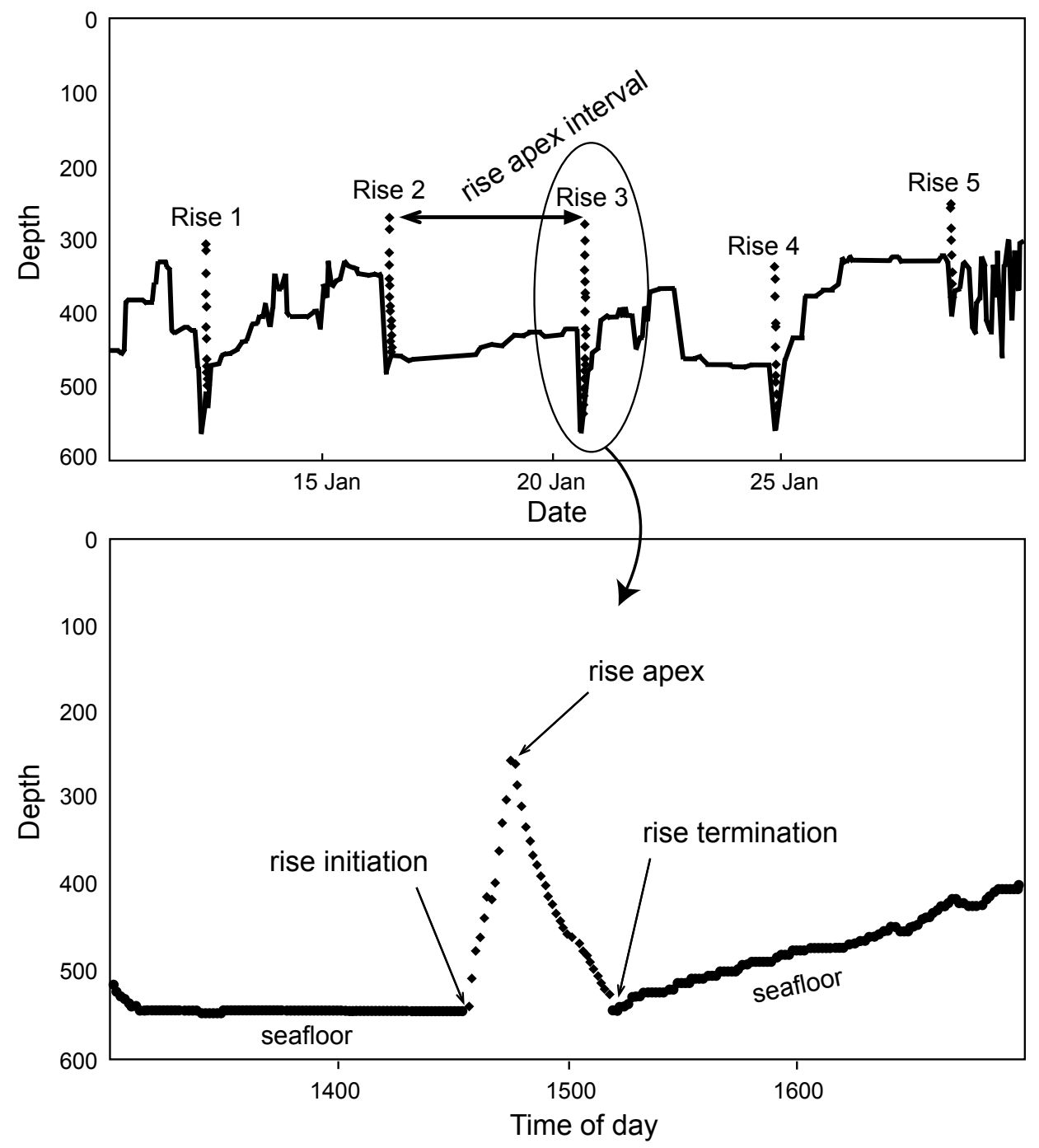

Fig. 5. Water depth occupied by a Pacific halibut over the course of twenty days during which it conducted a series of five spawning rises (upper panel), and one of those rises depicted at a temporal resolution of 4 hours (lower panel). Data points are separated by one minute time intervals. Terms used in this paper to describe the behavior are indicated. 


\section{Maturity estimation}

A conservative estimate of size-specific maturity within the tagged population was conducted in order to assess the likelihood that fish failing to undergo an offshore migration or exhibit spawning rises simply represented immature individuals. Size and maturity data from the 2006 IPHC setline survey were used to derive a schedule of size-specific maturity probabilities for all Gulf of Alaska female halibut. Cumulative immaturity probability $\left(\operatorname{Im} m_{\text {cum }}\right)$ for the tagged population was then estimated as:

$$
I m_{\text {cum }}=\sum_{n=1}^{n} F L_{n} P_{i l},
$$

where $=F L_{\mathrm{n}}=$ fork length of the $n^{\text {th }}$ fish, and $P_{\text {il }}=$ proportion of the coastwide population that was immature at that length. The result is the number of tagged fish expected to be immature, given the size-distribution of the tagged population and assuming that all tagged fish were female. Although the latter assumption is likely to be false, using a female maturity ogive ensures that the estimated number of immature fish is a liberal one. Halibut display marked sexual dimorphism with considerably larger size-at-maturity in females (Clark et al., 1999). Thus, use of the female ogive should result in some small mature males being falsely assigned as immature, instead of large immature females being falsely assigned as mature. Unfortunately, applying such an assumption is necessary because sex in halibut cannot be reliably determined in a non-invasive manner. A method of external examination was presented by St. Pierre (1992), but subsequent field tests (T. Loher, unpublished) suggest that classification accuracy may be a function of the experience of the sampler and the size of the fish, and the method does not provide a tangible record for later cross-validation. Furthermore, commercial fishermen are required to eviscerate fish at sea, so in cases where tagged fish are physically recaptured they cannot be sexed upon landing. Therefore, we do not know the sex of any of the fish tagged.

\section{Results}

\section{Tagging}

Data suitable for analysis were recovered from 72 tags: 56 that produced only data transmissions, appropriate for analysis of off-shore-onshore migration, and 16 that were physically recovered, providing detailed archival records amenable to analysis of migration as well as characterization of spawning behavior. Of the tags that only reported to satellites, 23 produced full-year records covering the winter of 2005-2006, 12 produced records extending through the winter of 2006-2007 to
$1 \mathrm{March}$, and 21 produced records through the winter of 2006-2007 to 15 February. None of the tags deployed in 2000 produced data transmissions because of an internal software error that prevented their release from their host fish (Seitz et al., 2003). However, three tags deployed in 2000 were physically recovered after collecting data throughout the winter of 2000-2001: recovery dates were April 2001, September 2002, and June 2006. An additional 13 tags were physically recovered from the latter deployments. Eight tags from 2005 deployments were recaptured prior to their programmed release dates, with recapture dates that ranged from 5 March to 29 May 2006. Two tags from 2005 deployments were found awash following successful release and transmission after 365 days at-liberty. Three tags from 2006 deployments were found awash after release: two from the 15 February transmission group and one from the 1 March group.

\section{Spawning rises}

Of the 16 halibut for which detailed archival data were available, ten displayed a highly regular series of spawning rises (Fig. 6). These series were comprised of $6-10$ individual rises (mean $=7.0 \pm 0.51$ ), separated by intervals that averaged just under four days at $92 \pm 1.8 \mathrm{hr}$ (range $=71-133 \mathrm{hr}$ ). The complete duration of these spawning rise series within individual fish, from initiation of first spawning rise to completion of the last, ranged from $17-42$ days with a mean of $23 \pm 2.9$ days. The mean magnitude of individual spawning rises was $168 \pm 9.6 \mathrm{~m}($ range $=39-324 \mathrm{~m})$, with an ascent rate that was on average roughly $40 \%$ faster than the descent rate $\left(34 \pm 2.0 \mathrm{~m} \mathrm{~min}^{-1}\right.$ vs. $\left.25 \pm 2.0 \mathrm{~m} \mathrm{~min}^{-1}\right)$. Spawning was initiated from depths ranging from 278-594 m, a mean peak spawning depth of $422 \pm 9.7 \mathrm{~m}$ (Fig. 6a). Spawning rises were observed from December 27 to March 14, with a mean peak spawning date of 31 January \pm 2 days (Fig. 6b).

An eleventh fish (Fig. 6) conducted rises that did not fit the general pattern of the previously described fish. This individual conducted a large number of ascents, spaced at highly irregular intervals, and typically of smaller magnitude than other fish. Between 8 December and 23 January, it conducted 37 rises of an average of $77 \pm 5.0 \mathrm{~m}$ in magnitude, at average intervals of $31 \pm 7.9 \mathrm{hrs}$. Initiation depths ranged from $230-378 \mathrm{~m}$, mean peak depth of $276 \pm 5.5 \mathrm{~m}$ (Fig. 6a). Dates ranged from December 8 to January 23, with a mean peak of December $31 \pm$ two days (Fig. 6b).

The remaining five halibut for which detailed records were available failed to conduct ascents of marked 

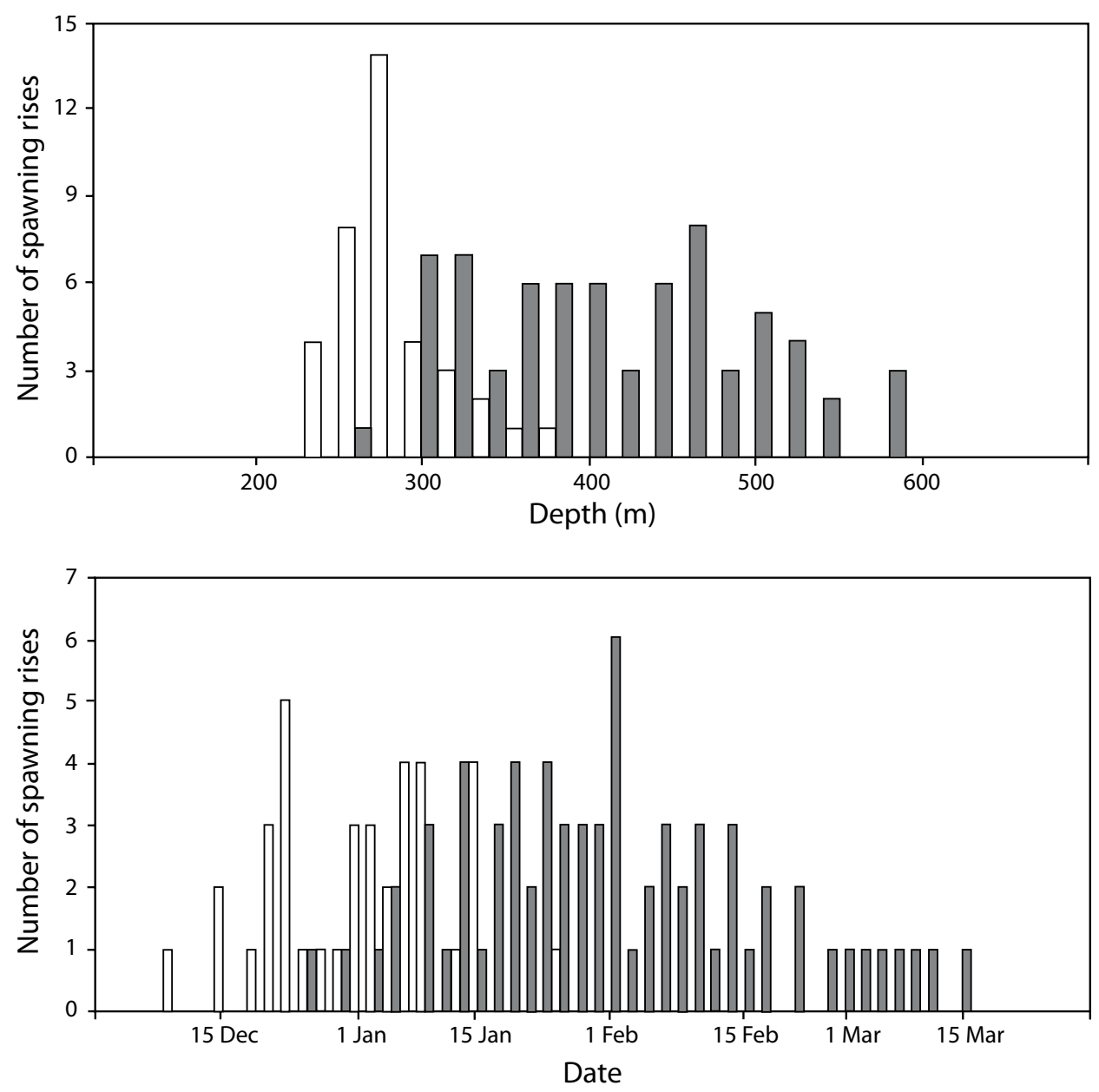

Fig. 6. Rise initiation depths (upper panel) and dates (lower panel) for the ten fish (solid bars) that each displayed series of 6-10 regularly-spaced spawning rises, and the eleventh fish (open bars) that conducted 37 rises with highly variable spacing.

magnitude or rapidity. This included two fish that at no time descended to the minimum observed rise initiation depth $(230 \mathrm{~m})$, and three that descended to similar depths as those fish in which rises were observed.

\section{Offshore migration}

Based upon halibut that conducted spawning rises, a minimum depth of $200 \mathrm{~m}$ was chosen to define active spawning depth. For the five fish that bore physically recovered tags and failed to conduct rises, maximum daily depth profiles indicated that three had descended to observed spawning depth during winter, whereas two remained on the continental shelf. Including fish for which only data transmissions were available, $16 \%$ of all tagged halibut remained on the shelf during spawning season. Daily maximum depth profiles revealed four patterns of seasonal vertical activity (Fig. 7) into which all fish could be classified: 1) summer residence on the continental shelf ( $<200 \mathrm{~m}$ depth) followed by at least some degree of winter slope-residence ( $n=54$ fish), 2) use of slope habitat throughout the year with no obvious offshore migration phase $(n=6), 3)$ use of slope habitat in summer followed by movement to the shelf in autumn $(n=1)$, and 4) full-time shelf residence $(n=11)$. The latter two categories represent fish deemed not to have undertaken the spawning migration $(n=12)$.

Based on the 2006 GoA female maturity schedule (Fig. 1) and the size distribution of the tagged halibut (Fig. 3), fewer than five individuals $\left(\operatorname{Im}_{\text {cum }}=4.60\right)$ were likely to be immature. Assuming that five tagged halibut were immature and further assuming that all of these fish can be subtracted from the subset that failed to move offshore, we estimate that seven mature halibut $(10 \%$ of the adult population) failed to participate in the seasonal spawning migration. The halibut that conducted the offshore migration but failed to display vertical rise 
behavior were $107 \mathrm{~cm}, 130 \mathrm{~cm}$, and $156 \mathrm{~cm}$ fl. Based on the female maturity ogive, these lengths correspond to $83 \%, 97 \%$ and $100 \%$ probability, respectively, of being mature.

\section{Discussion}

Archival data provide a method for quantifying season and habitat associated with active spawning, defined as release of reproductive products into the water col- umn. Present understanding of spawning season in halibut was derived from observations of gonad characteristics, egg ripeness and likely spawning status (St. Pierre, MS 1984), and surveys of egg abundance (Van Cleve and Seymour, MS 1953). Gonad examination is relatively easy to conduct, but spawning schedules can not be ascertained without histological sampling and an understanding of the relationship between egg hydration and the time-to-release. Egg surveys are a better method to infer timing and intensity of spawning, because they
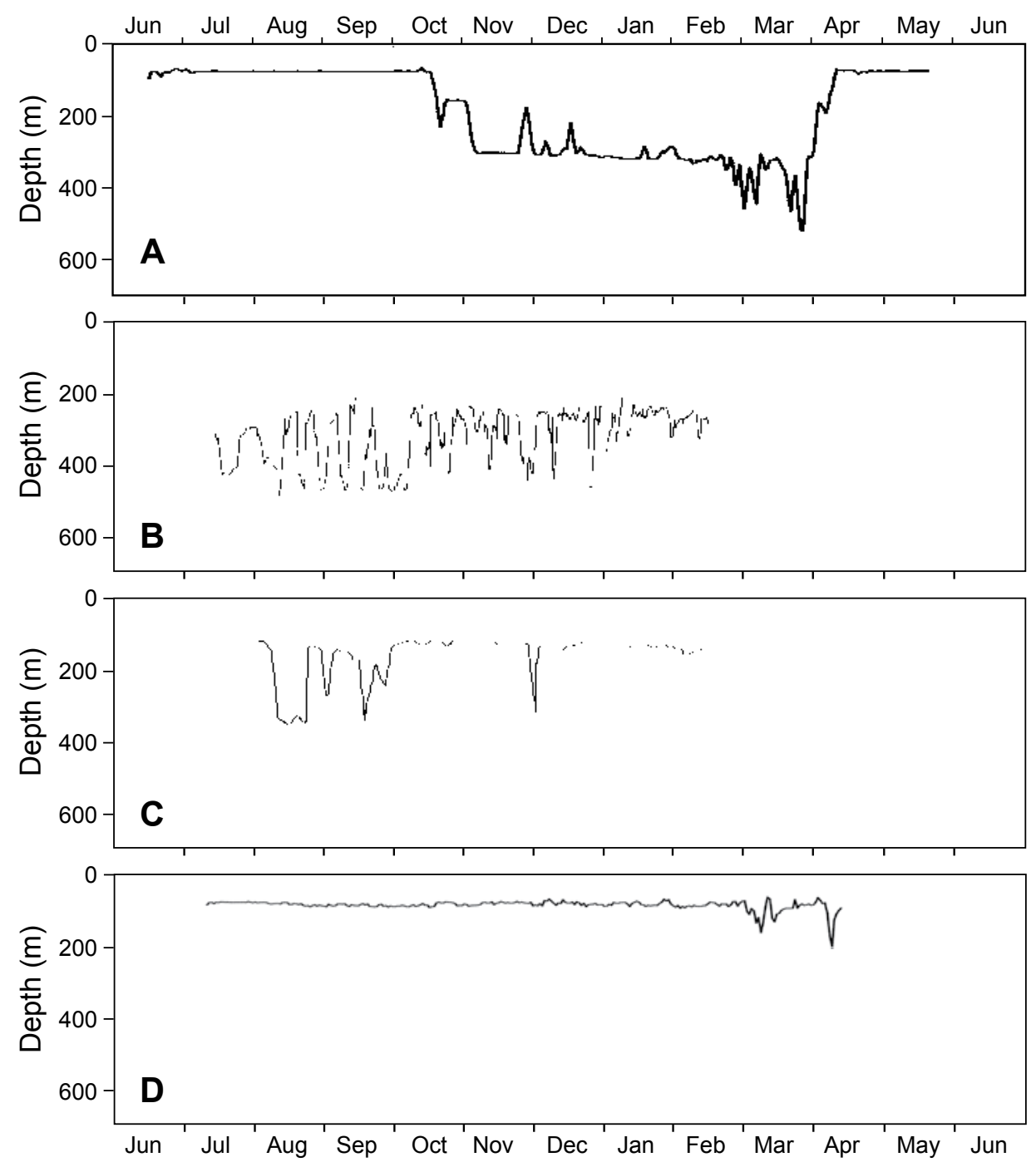

Fig. 7. Two-day averaged maximum depth profiles for four Pacific halibut that demonstrate the general seasonal behaviors observed across all tagged fish $(n=72)$. A) Summer residence on the continental shelf with an offshore autumn migration and occupation of deep slope waters in winter ( $n=54$ fish). B) Use of continental slope habitat throughout the year $(n=6)$. C) Use of slope habitat in summer and shelf residence in autumn and winter $(n=1)$. D) Full-time shelf residence $(n=11)$. Gaps in the depth profiles of fish depicted in panels $\mathbf{B}$ and $\mathbf{C}$ represent data that were not received during satellite transmissions; tags for the fish depicted in panels $\mathbf{A}$ and $\mathbf{D}$ were physically recovered. 
directly observe reproductive output, but are expensive and labor-intensive. Thus, to date there has been no practical way to quantitatively estimate the proportion of egg production released on any given date, or compare population-level spawning schedules temporally or spatially. The present analysis demonstrates a method whereby seasonal egg production could be quantitatively modeled, given larger sample sizes. Archival tagging data could be used to estimate skipped spawning rates and quantify the proportion of mature stock spawning at each size class. Size-specific fecundity relationships could then be applied to adjusted spawning biomass estimates to yield yearly egg production (sensu Rideout and Rose, 2006).

Of some interest is the striking difference in vertical rise behavior observed in one halibut (S-05011) relative to the others. For most fish, a highly regular interval between spawning rises and discrete period of occurrence matches well with wintertime batch-spawning in halibut (St. Pierre, MS 1984), and the vertical profiles match off-bottom external fertilization observed in other flatfish (Moyer et al., 1985; Konstantinou and Shen, 1995; Manabe et al., 2000; Manabe and Shinomiya, 2001; Carvahlo et al., 2003). For S-05011, the nature of its behavior is less clear. Halibut actively forage in the water column, as evidenced by pelagic prey in their diet (Best and St. Pierre, MS 1986; Orlov, MS 1997; Yang, MS 1997) and incidental capture in troll fisheries (Gilroy et al., MS 2004). The behavior of S-05011 could be ascribed to off-bottom foraging, but we hypothesize that it represents male spawning whereas the other observations were of females. Its rises were observed only during the spawning season and were initiated from similar depths and with vertical abruptness similar to the other fish. Its behavior deviated primarily in terms of frequency of rises and the extremely variable period between them. Because males are not constrained to an egg hydration schedule, they may be able to spawn with multiple partners, conducting rises whenever they locate a mate. Unfortunately, we do not know the sex of any of the tagged fish and can only present this as a hypothesis; future tagging should seek to determine sex at time of tagging, perhaps via veterinary ultrasound (sensu Martin-Robichaud and Rommens, 2001).

Although sample size was small and additional data are likely to broaden the observed range of spawning, the remaining data generally corroborate earlier work suggesting a November-March spawning season (St. Pierre, MS 1984), while simultaneously suggesting a peak that is somewhat later than our present assumption of December-January (Leaman et al., MS 2002). Lack of observed spawning behavior in November-December could simply reflect the difference between the present definition of spawning (putative egg release) and earlier metrics based upon depth distribution and presence of ripe females on sampled grounds. Autumn may consist of pre-spawn aggregation, oocyte maturation, and courtship behavior. Regardless, spawning extending well into March represents a later peak spawning period, and analysis of depth profiles (Loher and Seitz, MS 2008) confirms that much of the tagged population remained on deepwater grounds into April. The population may have shifted towards later spawning in recent years, or there may be a larger degree of interannual variability than previously acknowledged. Variability in spawn-timing can be species- and stock-specific, in terms of both trend and magnitude. For example, peak spawning of Atlantic cod in the Baltic Sea, from at least 1986-1998, occurred progressively later each year, advancing by a total of nearly three months (Wieland et al., 2000). Temperature may yield a similar magnitude of variance in North Sea dab (Limanda limanda), but generally without linear trend (Lange and Greve, 1997). Harding et al., (1978) has also reported non-trended interannual variability for North Sea plaice (Pleuronectes platessa), but varying only by weeks.

At present we can say nothing specific regarding interannual variability in peak spawning of eastern halibut. But the present data indicate that GoA fisheries prosecuted prior to $15 \mathrm{March}$, in waters deeper than $\sim 200-250 \mathrm{~m}$, are likely to impact spawning fish. If protection of spawning stock remains a priority, a conservative approach might be to do so over a relatively broader period than previously reported, at least until we gain a greater understanding of spawning dynamics. Effects of fishing on spawning aggregations have been demonstrated in other species harvested via hook-and-line. Striking changes in sex-ratio and male size structure of Tasmanian calamary (Sepioteuthis australis) occur shortly after the opening of spawning-season fisheries (Hibberd and Pecl, 2007). It is hypothesized that accumulation of males on the grounds and their tendency to remain stationary makes them more vulnerable than females (Hibberd and Pecl, 2007). In Gulf of Mexico grouper (Serranidae), increased male selectivity due to aggregation may cause seasonal changes in sex ratio (Coleman et al., 1996). Winter fisheries for halibut might also result in different size- or sex-specific mortality rates than occur in summer, given the documented size- and sex-specific selectivity for the species (Skud and Hamley, MS 1978; Løkkeborg and Bjordal, 1992; Stoner and Ottmar, 2004; Clark, MS 2006). Additionally, a large proportion of the mature male population is of sublegal size due to sexually dimorphic growth and 
maturation (Clark et al., 1999). Winter fisheries could subject mature males to capture and subsequent discard while they are participating in spawning, which could reduce mean reproductive success if capture stress affects breeding performance, either behaviorally (Philipp et al., 1997; Lowerre-Barbieri et al., 2003) or physiologically (Wells, 1987; Meeotti et al., 1992).

In addition, fishing pressure applied during only a portion of the spawning season could have unforeseen consequences. Modest increases in season length have been allowed in the commercial halibut fishery, applied only during the latter portion of the spawning season (February-March). Altered run timing and reproductive dynamics due to temporally-explicit fishing mortality have been reported in species as disparate as south Pacific calamary (Moltschaniwskyj and Pecl, 2007) and Atlantic salmon (Salmo salar; Quinn et al., 2006). For anadromous species, genetic determinants of run timing have been well studied (Varnavskaya et al., 1994; Stewart et al., 2002; Narum et al., 2004), and Alaskan salmon stocks are managed to distribute mortality across runs to avoid fishery-induced selection in spawn timing (Flynn et al., 2006). In halibut, it is not known whether older and more fecund females spawn during a specific portion of the season, nor whether variability in reproductive timing is genetically controlled. Even if timing is interannually plastic and therefore not subject to fishery-induced selection, removing spawning stock during only a portion of the season may shorten the population's larval period. Spawning periods may evolve to match environmental variability (see reviews in Houde, 1987; Cushing, 1990) and a prolonged spawning period may be a form of environmental bet-hedging to safeguard against recruitment failure. Halibut recruitment is believed to be environmental driven, via either favorable plankton productivity or larval transport (Clark and Hare, 2002). Considerable temporal variability in these processes exists in both the Gulf of Alaska (Bailey and Picquelle 2002; Dagg et al., 2006) and Bering Sea (Coyle and Hunt, 2000; Mizobata and Saitoh, 2004).

While tagging cannot elucidate causes of spawning omission, the present data also support the hypothesis that a non-trivial proportion of sexually mature eastern halibut may forego spawning in any given year. Our results suggest that $\sim 20-25 \%$ of adults either fail to participate in the spawning migration or do not conduct spawning rises once on the winter grounds. These halibut may employ an alternative spawning strategy that does not involve vertical off-bottom rises, or deep-water wintertime vertical rises may not represent active spawning, as we believe. Alternatively, it is possible that the absence of these behaviors was due to tag-induced stress, and therefore an artifact of the study design. However, we feel that skipped spawning represents the most parsimonious explanation for the correlation between full-time shelf residence and absence of vertical rises, and that skipped spawning is reasonable to expect in the natural population. Skipped spawning is widespread in Teleosts (see review in Rideout et al., 2005), commonly attributed to poor nutritional condition, and may increase lifetime reproductive success in long-lived migratory species (Jorgensen et al., 2006). Skipped spawning in halibut is also evident in historical data. In the Bering Sea, Novikov (1964) observed that "at the end of the spawning season, among the spent fish there are quite a few individuals ... which did not participate in spawning", and concluded that egg maturation may not be possible every year. Leaman et al. (MS 2002) dismissed this because "a two-year ova maturation process would be very unusual in the spectrum of demersal fishes in the north Pacific Ocean." However, these observations are not mutually exclusive in the context of skipped spawning. Fish that do not participate in spawning in a given season may not be in the first year of a two-year maturation cycle, but rather fish that are not ripening ova at all. Novikov's observations may indicate high rates of skipped spawning in northern waters where cold temperatures or trophic factors impose long post-spawn recovery periods.

An argument might be made that skipped spawning can be ignored, in the context of IPHC survey design, because individuals preparing to skip the upcoming spawning should be classified as immature on the basis macroscopic gonad examination. Thus, the resulting ogive (Fig. 1) would describe the proportion of fish expected to spawn at any given size, rather than represent a maturity curve, per se. As such, estimates of spawning biomass should remain robust, regardless of the fact that skipspawners are misclassified as immature. However, the present results counter this hypothesis. If true, the proportion of skipped spawners predicted from archival tagging data, at any given size, would be equivalent to the proportion of non-spawners estimated from the ogive. Here, we present the residual between the two methods: the proportion of apparent non-spawners that cannot be identified as such during the survey. The fact that some degree of skipped spawning is likely incorporated into estimates of immature fish is a limitation to perfectly estimating rates of skip-spawning via the present method. But in this context, our estimates of skipped spawning should therefore be conservative.

The IPHC acknowledges the importance of maintaining spawning stock biomass above the historical 
minimum. The current management strategy includes biomass limit reference points to trigger changes in harvest rate, and a provision to cease harvest should spawning biomass reach the historical minimum (Clark and Hare, MS 2006). The foundation of such a policy lies in the relationship between spawning stock biomass, expected recruitment, and the population's ability to recover from declines in abundance. However, if not all mature fish spawn, then the relationship between total mature biomass and effective spawning biomass may be temporally and spatially dynamic. Recruitment potential may depend upon mean fish condition across the population, expressed as total fecundity and rates of skipped spawning. In order to fully safeguard population reproduction potential it may be necessary to maintain higher mature stock abundance during periods when skipped spawning is prevalent than in years when a large proportion of spawners successfully contribute to recruitment.

In summary, we should seek a fuller understanding of halibut reproductive dynamics and of spatial and temporal variability in spawning success. Archival tagging represents a method that can be used to quantify the season of egg release and depths occupied by actively spawning fish, and potential rates of skipped spawning. Rideout et al. (2005) discuss the utility of conventional tagging for examining rates of skipped spawning based on the presence or absence of tagged fish in annual spawning surveys. They distinguish between species in which non-spawners remain spatially segregated from spawners (e.g., orange roughy (Hoplostethus atlanticus); Bell et al., 1992) and those in which nonspawners join spawning aggregations (e.g., Atlantic cod (Gadus morhua); Rideout et al., 2005). They point out that in cases where segregation is maintained, absence of tagged individuals from sampled aggregations may indicate failure to spawn but can also simply reflect lack of site fidelity, and that in mixed aggregations the presence of tagged individuals within the spawning groups does not confirm active participation in spawning, per $s e$. In halibut, it appears that a combination of behaviors may be associated with skipped spawning: some fish fail to join the offshore spawning migration, and others may join aggregations but fail to actively spawn. An advantage of archival tagging in this species is the ability to resolve both behaviors, as well as to identify behavior that is consistent with spawning in individuals that fail to display fidelity to known grounds. Sex-determination during tagging could further allow for investigation of sex- and age-specific differences in reproductive and migratory behavior, and might be combined with genetics to test hypotheses regarding the basis of alternative strategies. Estimating rates of skipped spawning could allow us to better quantify effective spawning biomass and identify regional and temporal variance. The knowledge gained could serve management during discussions of season length, time-area closures, and harvest policy.

\section{Acknowledgements}

The authors wish to thank those who tagged halibut during this study: Amanda Barney, Levy Boiter, Dean Gaidica, Paul Logan, Ivan Loyola, Jen Lucke, Dan Rafla, Derek Wilson, Tom Wilson, and Antony Zanini, as well as the captains and crews of the fishing vessels Blackhawk, Bold Pursuit, Clyde, Free to Wander, Pender Isle, Predator, Proud Venture, Rocinante, Star Wars II, Viking Joy, and Waterfall. Claude Dykstra, Kelly Ames, Tracee Geernaert, Erica Anderson, and Eric Soderlund provided valuable logistical assistance through the IPHC setline survey program, and our anonymous reviewers provided comments that improved the quality of the final manuscript.

\section{References}

BAILEY, K. M., and S. J. PICQUELLE. 2002. Larval distribution of offshore spawning flatfish in the Gulf of Alaska: potential transport pathways and enhanced onshore transport during ENSO events. Mar. Ecol. Prog. Ser., 236: 205-217. doi:10.3354/meps 236205

BELL, J. D., J. M. LYLE, C. M. BULMAN, K. J. GRAHAM, G. M. NEWTON, and D. C. SMITH. 1992. Spatial variation in reproduction, and occurrence of non-reproductive adults, in orange roughy, Hoplostethus atlanticus, Collett (Trachichthyidae), from south-eastern Australia. J. Fish Biol., 40: 107-122. doi:10.1111/j.1095-8649.1992.tb02558.x

BEST E. A., and G. ST. PIERRE. MS 1986. Pacific halibut as predator and prey. Int. Pac. Hal. Comm. Tech. Rep., No. $21,27 \mathrm{p}$.

BURTON, M. P. M. 1999. Notes on potential errors in estimating spawning stock biomass: determining the effects of nonparticipatory adults for some groundfish species. J. Northw. Atl. Fish. Sci., 25: 205-213. doi:10.2960/J.v25.a18

CARVAHLO, N., P. ALFONSO, and R. S. SANTOS. 2003. The heremic mating system and mate choice in the wise-eyed flounder, Bothus podas. Env. Biol. Fish., 66: 249-258. doi:10.1023/A:1023957825568

CLARK, W. G. MS 2006. Effects of gear type, hook spacing, and hook size on commercial selectivity and catchability. Int. Pac. Halibut Comm Rep. Assmnt Res. Activ., 2003: 93-103.

CLARK, W. G., and S. R. HARE. 2002. Effects of climate and stock size on recruitment and growth of Pacific halibut. $N$. Am. J. Fish. Mgmt., 22: 852-862. doi:10.1577/1548-8675(2002)022<0852:EOCASS $>2.0 . C O ; 2$

MS 2006. Assessment and management of Pacific halibut: data, methods, and policy. Int. Pac. Halibut Comm. 
Sci. Rep., No. 83, 104 p. http://www.iphc.washington.edu/ halcom/pubs/scirep/SciReport0083.pdf

CLARK, W. G., S. R. HARE, A. M. PARMA, P. J. SULLIVAN, and R. J. TRUMBLE. 1999. Decadal changes in growth and recruitment of Pacific halibut (Hippoglossus stenolepis). Can. J. Fish. Aquat. Sci., 56: 242-252. doi:10.1139/ cjfas-56-2-242

COLEMAN, F. C., C. C. KOENIG, and L. A. COLLINS. 1996. Reproductive styles of shallow-water groupers (Pisces: Serranidea) in the eastern Gulf of Mexico and the consequences of fishing spawning aggregations. Env. Biol. Fish., 47: 129-141. doi:10.1007/BF00005035

COYLE, K. O., and G. L. HUNT. 2000. Seasonal differences in the distribution, density and scale of zooplankton patches in the upper mixed layer near the western Aleutian Islands. Plankton Biol. Ecol., 47: 31-42.

CUSHING, D. H. 1990. Plankton production and year-class strength in fish populations: an update of the match/mismatch hypothesis. Adv. Mar. Biol., 26: 249-294.

DAGG, M. J., H. LIU, and A. C. THOMAS. 2006. Effects of mesoscale phytoplankton variability on the copepods $\mathrm{NeO}$ calanus flemingeri and N. plumchrus in the coastal Gulf of Alaska. Deep Sea Res. I, 53: 321-332. doi:10.1016/j. dsr.2005.09.013

FLYNN, L., A. E. PUNT, and R. HILBORN. 2006. A hierarchical model for salmon run reconstruction and application to the Bristol Bay sockeye salmon (Oncorhynchus nerka) fishery. Can. J. Fish. Aquat. Sci., 63: 1564-1577. doi:10.1139/ F06-045

GILROY, H. L., T. M. KONG and T. G. GEERNAERT. MS 2004. 2003 commercial fishery and regulation changes. Int. Pac. Halibut Comm. Rep. Assmnt. Res. Activ., 2003, 33-43. http://www.iphc.washington.edu/halcom/pubs/ rara/2003rara/2k302RARA.pdf

HANSEN, L. P. and B. JONSSON. 1991. Evidence of a genetic component in the seasonal return pattern of Atlantic salmon, Salmo salar L. J. Fish Biol., 38, 251-258. doi:10.1111/ j.1095-8649.1991.tb03111.x

HARDING, D., J. H. NICHOLS, and D. S. TUNGATE. 1978. The spawning of plaice (Pleuronectes platessa L.) in the southern North Sea and English Channel. Rapp. P.-v. Reun. Cons. Int. Explor. Mer., 172: 102-113.

HEDE-JORGENSEN, H. B., M. M. HANSEN, and V. LOESCHCKE. 2005. Spring-spawning herring (Clupea harengus $L$.) in the southwestern Baltic Sea: do they form genetically distinct spawning waves? ICES J. Mar. Sci., 62: $1065-1075$.

HIBBERD, T., and G. T. PECL. 2007. Effects of commercial fishing on the population structure of spawning southern calamary (Sepioteuthis australis). Rev. Fish Biol. Fish., 17: 207-221. doi:10.1007/s11160-006-9028-4

HOUDE, E. 1987. Fish early life history dynamics and recruitment variability. Am. Fish. Soc. Symp., 2: 17-29.

JORGENSEN, C., B. ERNANDE, O. FISKEN, and U. DIECKMANN. 2006. The logic of skipped spawning in fish. Can. J. Fish. Aquat. Sci., 63: 200-211. doi:10.1139/f05210

KONSTANTINOU, H., and D. C. SHEN. 1995. The social and reproductive behavior of the eyed flounder, Bothus ocellatus, with notes on the spawning of Bothus lunatus and Bothus ellipticus. Env. Biol. Fish., 44: 311-324. doi:10.1007/BF00008245

LANGE, U., and W. GREVE. 1997. Does temperature influence the spawning time, recruitment and distribution of flatfish via its influence on the rate of gonadal maturation? Ger. J. Hydrogr., 49: 251-263. doi:10.1007/BF02764037

LEAMAN, B. M., T. O. GEERNAERT, T. LOHER, and W. G. CLARK. MS 2002. Further examination of biological issues concerning an extended commercial fishing season. Int. Pac. Halibut Comm. Bluebook, Part I., p. 39-58. http://www.iphc.washington.edu/halcom/pubs/ annmeet/2002/2002BBpt1.pdf

LøKKEBORG, S., and Á. BJORDAL. 1992. Species and size selectivity in longline fishing: a review. Fish. Res., 13: 311-322. doi:10.1016/0165-7836(92)90084-7

LOHER, T. 2008. Homing and summer feeding site fidelity of Pacific halibut (Hippoglossus stenolepis) in the Gulf of Alaska, established using satellite-transmitting archival tags. Fish. Res., 92: 63-69. doi: 10.1016/j. fishres.2007.12.013

LOHER, T., and A. SEITZ. 2006. Seasonal migration and environmental conditions of Pacific halibut Hippoglossus stenolepis in the Gulf of Alaska, elucidated from pop-up archival transmitting (PAT) tags. Mar. Ecol. Prog. Ser., 317: 259-271. doi:10.3354/meps317259

MS 2008. Characterization of seasonal onshoreoffshore migration timing, and active spawning depth and period of Gulf of Alaska halibut, with evidence of possible skipped spawning. Int. Pac. Halibut Comm. Rep. Assmnt Res. Activ., 2007: 433-450. http://www.iphc.washington. edu/halcom/pubs/rara/2007rara/2k7rara05.pdf

LOWERRE-BARBIERI, S. K., F. E. VOSE, and J. A. WHITTINGTON. 2003. Catch-and-release fishing on a spawning aggregation of common snook: does it affect reproductive output? Trans. Am. Fish. Soc., 132: 940-952. doi:10.1577/ T02-001

MANABE, H., and A. SHINOMIYA. 2001. Two spawning seasons and mating system of the bastard halibut, Tarphops oligolepis. Ichthyol. Res., 48: 421-424. doi:10.1007/ s10228-001-8167-9

MANABE, H., I. MIYUKI, and A. SHINOMIYA. 2000. Mating system of the lefteye flounder, Engyprosopon grandisquama. Ichthyol. Res., 47: 67-74. doi:10.1007/BF02674315

MARTIN-ROBICHAUD, D. J., and M. ROMMENS. 2001. Assessment of sex and evaluation of ovarian maturation of fish using ultrasound. Aquaculture Res., 32: 133-120. doi:10.1046/j.1365-2109.2001.00538.x

MEEOTI, P., A. RONCARATI, E. GARELLA, O. CARNEVALI, G. MOSCONI, and A. POLZONETTI-MAGNI. 1992. Effects of handling and capture stress on plasma glucose, cortisol and androgen levels in brown trout, Salmo trutta morpha fario. J. Applied Ichthyol., 8: 234-239. doi:10.1111/j.1439-0426.1992.tb00688.x

MIZOBATA, K., and S.-I. SAITOH. 2004. Variability of Bering Sea eddies and primary productivity along the shelf edge during 1998-2000 using satellite multisensor remote sensing. J. Mar. Sys., 50: 101-110. doi:10.1016/j. jmarsys.2003.09.014 
MOLTSCHANIWSKYJ, N. A., and G. T. PECL. 2007. Spawning aggregations of squid (Sepioteuthis australis) populations: a continuum of 'microcohorts'. Rev. Fish Biol. Fish., 17: 183-195. doi:10.1007/s11160-006-9025-7

MOYER, J. T., Y. YOGO, M. J. ZAISER, and H. TSUKAHARA. 1985. Spawning behavior and social organization of the flounder Crossorhombus kobensis (Bothidae) at Miyakejima, Japan. J. Jap. Ichthyol., 32: 363-367.

NARUM, S. R., M. S. POWELL, and A. J. TALBOT. 2004. A distinctive microsatellite locus that differentiates oceantype from stream-type Chinook salmon in the interior Columbia River basin. Trans. Am. Fish. Soc., 133: 1051-1055. doi:10.1577/T03-140.1

NOVIKOV, N. P. 1964. Basic elements of biology of the Pacific halibut (Hippoglossus stenolepis Schmidt) in the Bering Sea. In: Soviet Fisheries Investigation in the Northeastern Pacific, Part V. P. A. Moiseev (ed.). U.S. Dept. Commerce, Washington, DC, p. 175-219.

ORLOV, A. M. MS 1997. Role of fishes in predator diets of the Pacific slope of the northern Kuril Islands and southeastern Kamchatka. In: Forage Fishes in Marine Ecosystems. Lowell Wakefield Fisheries Symposia Series, Alaska Sea Grant College Program Report AK-SG-97-01, Anchorage, p. 209-229.

PHILIPP, D. P., C. A. TOLINE, M. R. KUBACKI, and D. B. F. PHILIPP. 1997. The impact of catch-and-release angling on the reproductive success of smallmouth bass and largemouth bass. N. Am. J. Fish. Manag., 17: 557-567. doi:10.1577/15488675(1997)017<0557:TIOCAR >2.3.CO;2

QUINN, T. P., P. MCGINNITY, and T. F. CROSS. 2006. Longterm declines in body size and shifts in run-timing of Atlantic salmon in Ireland. J. Fish Biol., 68: 1713-1730. doi:10.1111/j.0022-1112.2006.01017.x

RIDEOUT, R. M., and G. A. ROSE. 2006. Suppression of reproduction in Atlantic cod Gadus morhua. Mar. Ecol. Prog. Ser., 320: 267-277. doi:10.3354/meps320267

RIDEOUT, R. M., G. A. ROSE, and M. P. M. BURTON. 2005. Skipped spawning in female iteroparous fishes. Fish Fish., 6: 50-72. doi:10.1111/j.1467-2679.2005.00174.x

SEITZ, A., D. WILSON, B. L. NORCROSS, and J. L. NEILSEN. 2003. Pop-up Archival Transmitting (PAT) tags: a method to investigate the migration and behavior of Pacific halibut Hippoglossus stenolepis in the Gulf of Alaska. Alaska Fish. Res. Bull., 10: 124-136.

SEITZ, A., B. L. NORCROSS, D. WILSON, and J. L. NEILSEN. 2005. Identifying spawning behavior in Pacific halibut, Hippoglossus stenolepis, using electronic tags. Env. Biol. Fish., 73: 445-451. doi:10.1007/s10641-005-3216-2
SKUD, B. E., and J. M. HAMLEY. MS 1978. Factors affecting longline catch and effort. Int. Pac. Halibut Comm. Sci. Rep., No. 64, 66 p. http://www.iphc.washington.edu/halcom/ pubs/scirep/SciReport0064.pdf

SLOTTE, A., A. JOHANNESSEN, and O. S. KJESBU. 2000. Effects of fish size on spawning time in Norwegian springspawning herring. J. Fish Biol., 56: 295-310. doi:10.1111/ j.1095-8649.2000.tb02107.x

ST. PIERRE, G. MS 1984. Spawning locations and season for Pacific halibut. Int. Pac. Halibut Comm. Sci. Rep., No. 70, 46 p. http://www.iphc.washington.edu/halcom/pubs/scirep/ SciReport0070.pdf

1992. Visual determination of sex in live Pacific halibut. ICES. J. Mar. Sci., 49: 373-376. doi:10.1093/ icesjms/49.3.373

STEWART, D. C., G. W. SMITH, and A. F. YOUNGSON. 2002. Tributary-specific variation in timing and return of adult Atlantic salmon (Salmo salar) to fresh water has a genetic component. Can. J. Fish. Aquat. Sci., 59: 276-281. doi:10.1139/f02-011

STONER, A., and L. OTTMAR. 2004. Fish density and size alter Pacific halibut feeding: implications for stock assessment. J. Fish Biol., 64: 1712-1724. doi:10.1111/j.0022-1112.2004.00434.x

VAN CLEVE, R. and A. H. SEYMOUR. MS 1953. The production of halibut eggs on the Cape St. James spawning bank off the coast of British Columbia, 1935-1946. Int. Pac. Halibut Comm. Sci. Rep., No. 19, 44 p. http://www.iphc. washington.edu/halcom/pubs/scirep/Report0019.pdf

VARNAVSKAYA, N. V., C. C. WOOD, R. J. EVERETT, R. L. WILMOT, V. S. VARNAVSKAYA, V. V. MIDANAYA, and T. P. QUINN. 1994. Genetic differentiation of subpopulations of sockeye salmon (Oncorhynchus nerka) within lakes of Alaska, British Columbia and Kamchatka, Russia. Can. J. Fish. Aquat. Sci., 51 suppl 1: 145-155. doi:10.1139/f94-301

WELLS, R. M. G. 1987. Stress responses imposed by fish capture and handling: a physiological perspective. Food Technol., 39: 479-481.

WIELAND, K., A. JARRE-TEICHMANN, and K. HORBOWA. 2000. Changes in the timing of spawning of Baltic cod: possible causes and implications for recruitment. ICES J. Mar. Sci., 57: 452-464. doi:10.1006/jmsc.1999.0522

YANG, M.-S. MS 1997. Trophic role of Atka mackerel (Pleurogrammus monopterygius) in the Aleutian Islands. In: Forage Fishes in Marine Ecosystems. Lowell Wakefield Fisheries Symposia Series, Alaska Sea Grant Coll. Prog. Rep. AK-SG-97-01, Anchorage, p. 277-279. 